\title{
Sodium Bicarbonate Infusion Test: A New Method for Evaluating Parathyroid Function
}

\author{
YASUMASA IWASAKI, NORIKO MUTSUGA*, ETSUKO YAMAMORI*, AYAKO KAKITA*, \\ YUTAKA OISO*, TSUNEO IMAI**, HIROOMI FUNAHASHI**, YUJI TANAKA***, \\ KUNIKAZU KONDO ${ }^{\#}$ AND NOBUO NAKASHIMA \\ Departments of Clinical Pathophysiology, Nagoya University Graduate School of Medicine and Hospital, Nagoya 466-8550, Japan \\ * Departments of Internal Medicine, Nagoya University Graduate School of Medicine and Hospital, Nagoya 466-8550, Japan \\ **Departments of Surgery, Nagoya University Graduate School of Medicine and Hospital, Nagoya 466-8550, Japan \\ ***Department of Surgery I, Aichi Medical University, Nagakute 480-1195, Japan \\ \#Department of Internal Medicine, Anjo Kosei Hospital, Anjo 446-8602, Japan
}

\begin{abstract}
We have developed a new test for estimating the secretory capacity of parathyroid hormone (PTH) from the parathyroid gland. Sodium bicarbonate solution $\left[8.4 \%(\mathrm{w} / \mathrm{v}) ; 35 \mathrm{ml} / \mathrm{m}^{2}\right.$ body surface area] was infused for $2 \mathrm{~min}$, and blood samples for the determination of plasma ionized calcium, plasma PTH (intact, midregion, carboxy-terminus) and related parameters were serially obtained. In 8 healthy volunteers, the mean $( \pm \mathrm{SE})$ plasma ionized calcium fell promptly and significantly (from $1.21 \pm 0.01$ to $1.11 \pm 0.01 \mathrm{mmol} / \mathrm{L}$ ) after the sodium bicarbonate infusion. The mean $( \pm \mathrm{SE}$ ) plasma intact PTH increased promptly and significantly, by more than four fold ( $42.3 \pm 4.2$ to $182.4 \pm 34.7 \mathrm{pg} / \mathrm{ml})$, and then gradually returned to basal levels. In patients with partial hypoparathyroidism who have detectable basal plasma levels of PTH, the absolute increment in PTH levels was much less, and in the plasma obtained from patients with complete hypoparathyroidism, absolutely no response was observed. Plasma obtained from patients diagnosed with primary hyperparathyroidism (parathyroid adenoma or hyperplasia) has high basal PTH levels. The response to the sodium bicarbonate infusion in these patients was markedly blunted (less than a two-fold increase in all cases examined). No significant adverse effects were observed during the procedure. Therefore, the sodium bicarbonate infusion test is a simple and sensitive method to stimulate PTH release, and is clinically useful for evaluating parathyroid gland function.
\end{abstract}

Key words: Parathyroid hormone, Parathyroid gland, Hyperparathyroidism, Hypoparathyroidism, Calcium

(Endocrine Journal 50: 545-551, 2003)

A variety of provocative tests using regulatory factors have been developed and are being used clinically for evaluating endocrine functions. For example, glucose loading is applied for the diagnosis of diabetes mellitus, and hypothalamic releasing hormones such as corticotropin-releasing hormone or growth hormonereleasing hormone are used for evaluating anterior pituitary function. These tests using physiological

Received: November 27, 2002

Accepted: April 11, 2003

Correspondence to: Yasumasa IWASAKI, M.D., Ph.D., Department of Clinical Pathophysiology, Nagoya University Graduate School of Medicine and Hospital, 65 Tsurumai-cho, Showa-ku, Nagoya 466-8560, Japan stimuli are quite valuable not only for the diagnosis of a disease, but also in characterizing the function of endocrine organs in both the healthy and diseased states.

Regarding the parathyroid gland, however, few provocation tests have been used and/or examined clinically. A physiological regulator in determining the presence of parathyroid hormone (PTH) is extracellular ionized calcium, a decrease of which, through calcium-sensing receptors, stimulates the release of PTH and vice versa, thereby showing an inverse sigmoid curve-like relationship [1,2]. Ethylenediaminetetraacetic acid (EDTA) infusion has previously been developed for stimulating PTH release by lowering ionized calcium $[3,4]$, although it is not widely used 
now because of its' weak stimulatory potency and adverse cardiovascular effects.

In the present study, we propose a new test for evaluating parathyroid gland function using sodium bicarbonate. The principle is that an acute infusion of a relatively small amount of sodium bicarbonate solution causes a transient rise in blood $\mathrm{pH}$ followed by decreased ionized calcium concentration, which in turn potently stimulates the release of this hormone. We found that this procedure is a simple and safe way to stimulate PTH release, and can be used to evaluate the secretory reserve as well as the differential diagnosis of various parathyroid gland disorders.

\section{Patients and Methods}

\section{Subjects}

We studied eight healthy volunteers and ten patients with various parathyroid diseases (four patients with idiopathic or post-surgical hypoparathyroidism and six patients with primary hyperparathyroidism). Healthy volunteers [mean $( \pm \mathrm{SD})$ age, $34.0 \pm 4.1$ years (range, 29 to 43)] enrolled as control subjects in this study were found to have normal serum total calcium, serum inorganic phosphate, plasma ionized calcium, plasma PTH (intact, midregion, and carboxy-terminus), and no known diseases including those of an endocrine nature. Patients with primary hypoparathyroidism originally had hypocalcemia and hyperphosphatemia with normal or undetectable basal plasma PTH levels. Patients 1 and 3 in our study were diagnosed as having idiopathic hypoparathyroidism without a family history or any other abnormalities, whereas Patients 2 and 4 who had undergone thyro-parathyroidectomy for the removal of a thyroid neoplasm developed postsurgical hypoparathyroidism. However, subcutaneous transplantation of the parathyroid gland was carried out in Patient 2 and thus PTH secretion remained. Patients 3 and 4 were on a low dose vitamin $\mathrm{D}_{3}$ and calcium lactate replacement therapy to maintain normal serum calcium levels, although administration of these medications was prohibited in the morning of the examination. Patients with primary hyperparathyroidism, in contrast, were shown to have hypercalcemia and hypophosphatemia with high basal plasma PTH, the diagnosis being confirmed by subsequent histological examinations (parathyroid adenoma in Patients 6 to 10 , and hyperplasia in Patient 5). Clinical profiles of the patients enrolled are summarized in Table 1. Informed consent was obtained from all patients and healthy subjects enrolled in this study. The protocol for this study was reviewed and approved by the Ethical Committee at the Nagoya University School of Medicine.

\section{Clinical studies}

The test was performed as follows. In fasting or at least $4 \mathrm{~h}$ postprandial states, $35 \mathrm{ml}$ per body surface

Table 1. Clinical profiles of the patients with parathyroid diseases

\begin{tabular}{|c|c|c|c|c|c|c|}
\hline Patients & $\begin{array}{l}\text { Age } \\
\text { (years) }\end{array}$ & Gender & Diagnosis & $\begin{array}{l}\left.\text { Serum calcium }{ }^{a}\right) \\
(\mathrm{mg} / \mathrm{dl})\end{array}$ & $\begin{array}{c}\text { Serum inorganic } \\
\text { phosphate }^{\mathrm{b})} \\
(\mathrm{mg} / \mathrm{dl})\end{array}$ & $\begin{array}{c}\text { Parathyroid } \\
\text { hormone intact }{ }^{\mathrm{c}} \\
(\mathrm{pg} / \mathrm{ml})\end{array}$ \\
\hline 1 & 28 & Male & hypoparathyroidism (partial, idiopathic) & 9.6 & 4.5 & 11.3 \\
\hline 2 & 43 & Female & hypoparathyroidism (partial, postoperative) & 8.9 & 3.7 & 10 \\
\hline 3 & 49 & Male & hypoparathyroidism (complete, idiopathic) ${ }^{\mathrm{d})}$ & 8.9 & 3.9 & $\mathrm{UD}^{\mathrm{e})}$ \\
\hline 4 & 48 & Female & hypoparathyroidism (complete, postoperative) d) & 10.2 & 3.6 & $\mathrm{UD}^{\mathrm{e})}$ \\
\hline 5 & 61 & Female & parathyroid hyperplasia & 10.8 & 2.7 & 464 \\
\hline 6 & 52 & Male & parathyroid adenoma & 10.4 & 2.6 & 295 \\
\hline 7 & 54 & Female & parathyroid adenoma & 10.4 & 3.5 & 180 \\
\hline 8 & 71 & Female & parathyroid adenoma & 10.9 & 2.5 & 144 \\
\hline 9 & 22 & Female & parathyroid adenoma & 11.2 & 2.0 & 118 \\
\hline 10 & 72 & Female & parathyroid adenoma & 10.9 & 2.8 & 80 \\
\hline
\end{tabular}

a) Normal range, $8.4-10.2 \mathrm{mg} / \mathrm{dl}$; ${ }^{\text {b) }}$ Normal range, $2.9-4.5 \mathrm{mg} / \mathrm{dl}$; ${ }^{\text {c) }}$ Normal range, $10-65 \mathrm{pg} / \mathrm{ml}$; ${ }^{\text {d) }}$ Under Vitamin $\mathrm{D}_{3}$ replacement therapy; ${ }^{\text {e) }} \mathrm{UD}$, undetectable.

Urinary calcium excretion (calcium/creatinine ratio) is not determined in this study. 
area $\left(\mathrm{m}^{2}\right)$ of $8.4 \%(\mathrm{w} / \mathrm{v})$ sodium bicarbonate solution (Otsuka Pharmaceutical Co., Tokyo, Japan) was injected into the ante-cubital vein over $2 \mathrm{~min}$. Blood samples were obtained from the ante-cubital vein of the other arm before and 3, 5, 10, 30, and $60 \mathrm{~min}$ following the start of infusion. Total serum calcium and other biochemical parameters were measured by automated techniques. Samples for the determination of ionized plasma calcium and blood bicarbonate ion concentrations were collected into heparinized $1 \mathrm{ml}$ syringes for immediate measurements. Blood samples to be used in the analysis of plasma PTH (intact, midregion, and C-terminus) concentrations were collected into tubes containing EDTA, centrifuged, and kept frozen at $-30^{\circ} \mathrm{C}$ for subsequent analysis. Body surface area was calculated by the equation: $\mathrm{A}=\mathrm{W}^{0.444} \times \mathrm{H}^{0.663} \times 88.83\left(\mathrm{~A}\right.$, body surface area $\left[\mathrm{m}^{2}\right]$; $\mathrm{W}$, body weight $[\mathrm{kg}] ; \mathrm{H}$, body height $[\mathrm{cm}])[5]$.

\section{Biochemical analyses}

Ionized plasma calcium was measured with an Easy-Ca analyzer (Medica corporation, Bedford, MA, USA). Blood $\mathrm{pH}$ and bicarbonate ion concentrations were measured with an ABI 320 blood gas analyzer (Radiometer, Copenhagen, Denmark). Plasma PTH was determined by three different assays: Intact PTH IRMA kit 'Mitsubishi' (Mitsubishi Chemical Co., Tokyo, Japan; normal range $14-66 \mathrm{pg} / \mathrm{ml}$ ) [6], a double-antibody immunoradiometric assay for the determination of intact PTH; a PTH RIA kit 'YAMASA' using antiserum (CH9) against the midregion of PTH (Yamasa Shoyu, Tokyo, Japan; normal range, $90-270 \mathrm{pg} / \mathrm{ml}$ ) [7] was used in the analysis of the midregion PTH; and a PTH-C RIA kit using antiserum against the carboxy-terminus of PTH (Immuno-Nuclear Co., Tokyo, Japan; normal range, below $0.6 \mathrm{ng} / \mathrm{ml}$ ) [8] was used in the analysis of the carboxy-terminus PTH. In addition, intact PTH was measured with an Allegro Intact PTH radioimmnometric assay kit (Nicholas Institute Diagnostics, San Juan Capistrano, CA, USA) [9, 10] which provides virtually identical results to those obtained by the 'Mitsubishi' assay.

\section{Statistical analysis}

Estimates of change over time were made with repeated-measures analysis of variance (ANOVA).
All statistical tests were two-tailed. A p-value of below 0.05 was considered significant.

\section{Results}

In eight healthy volunteers, the mean blood $\mathrm{pH}$ and bicarbonate ion concentrations were found to be significantly increased immediately following the sodium bicarbonate injection, after which a decrease in the mean $( \pm \mathrm{SE})$ ionized plasma calcium concentration was observed (from $1.21 \pm 0.01$ to $1.11 \pm 0.01$ $\mathrm{mmol} / \mathrm{L}$ ) (Fig. 1). The significant decrease in ionized calcium was maintained throughout the test period (until 60 min after the injection).

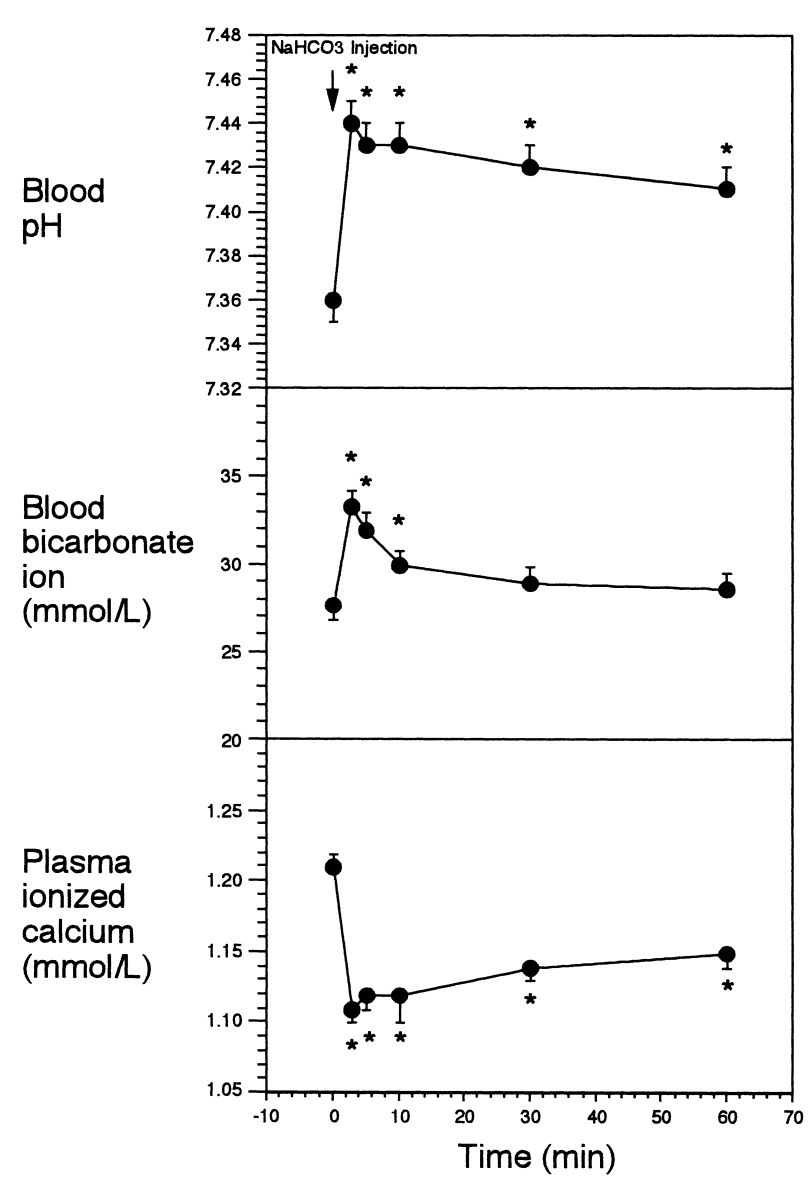

Fig. 1. Effects of sodium bicarbonate infusion on plasma ionized calcium and related parameters in eight healthy volunteers. Upper, middle, and lower panels show the mean $( \pm \mathrm{SE})$ blood $\mathrm{pH}$, blood bicarbonate ion, and plasma ionized calcium, respectively, before and after the sodium bicarbonate infusion. ${ }^{*} \mathrm{p}<0.05$ vs. the value at time zero. 
In response to the decrease in plasma ionized calcium, a prompt and marked rise in the mean $( \pm \mathrm{SE})$ intact plasma PTH levels $(42.3 \pm 4.2$ to $182.4 \pm 34.7$ $\mathrm{pg} / \mathrm{ml}$ ) was observed already 3 min after the start of the sodium bicarbonate infusion, and rapidly returned to basal levels (Fig. 2). Similar responses of midregion and carboxy-terminus PTH levels were observed, although the fold increases were less than that of intact PTH.

In plasma samples obtained from patients diagnosed with hypoparathyroidism (Patients 1 to 4), on the other hand, a diminished or no response in intact PTH was observed (Figs. 3A and 3B). The response was absent in two patients (Patients 3 and 4) with complete hypoparathyroidism with undetectable basal plasma PTH levels. Furthermore, in two patients with partial hypo-

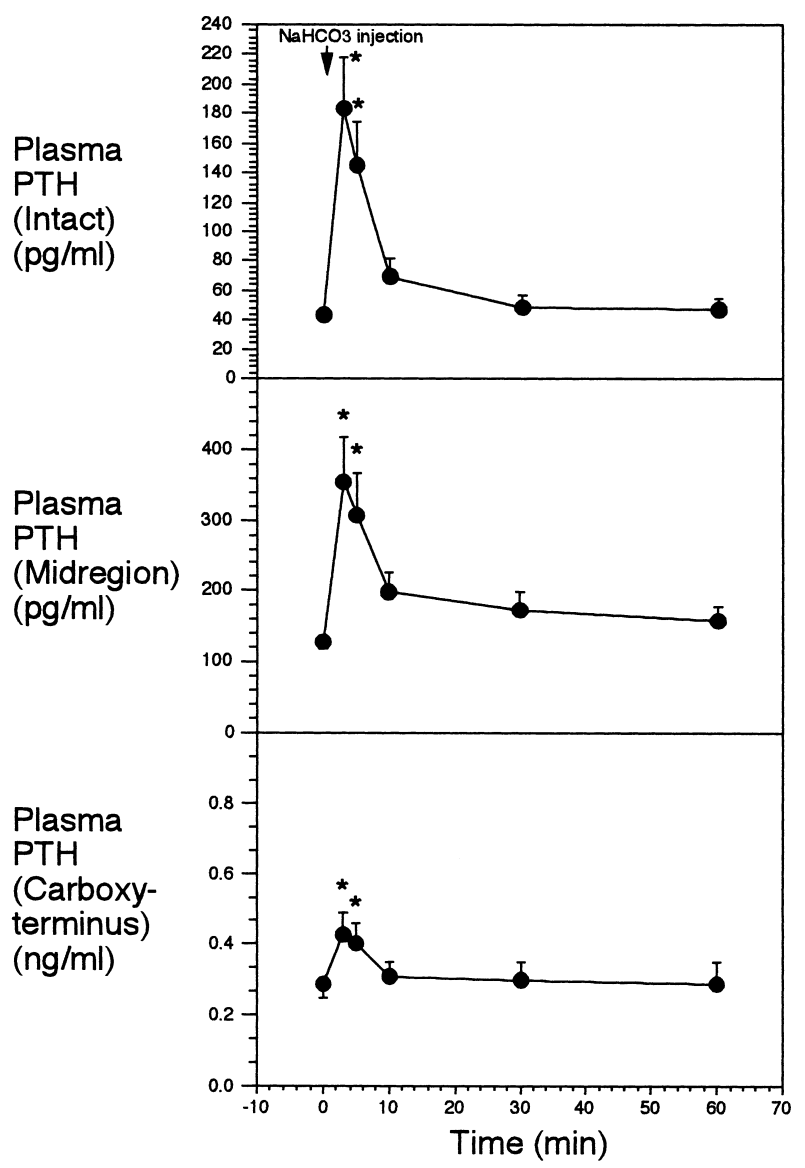

Fig. 2. Effects of sodium bicarbonate infusion on plasma PTH levels in eight healthy volunteers. Upper, middle, and lower panels show the mean $( \pm \mathrm{SE})$ intact, midregion, and carboxy-terminus PTH concentrations, respectively, before and after the sodium bicarbonate infusion. $* \mathrm{p}<0.05$ vs. the value at time zero. parathyroidism (Patients 1 and 2) with near-normal basal plasma PTH levels, minimal or virtually no increment in hormone levels (peak value minus basal value) was observed in response to sodium bicarbonate infusion (Fig. 3B). Changes in ionized plasma calcium and blood bicarbonate concentrations during the test in each patient are shown in Table 2.

In plasma samples obtained from patients diagnosed with primary hyperparathyroidism (Patients 5 to 10), intact PTH responses to sodium bicarbonate infusion were maintained in most of the patients (Fig. 4A). However, the fold increases (peak value divided by the basal value) of the hormone were much lower (1.9fold or less) than those of healthy volunteers (4.3-fold increase on average) (Fig. 4B). In one patient with parathyroid adenoma (Patient 9), absolutely no re-
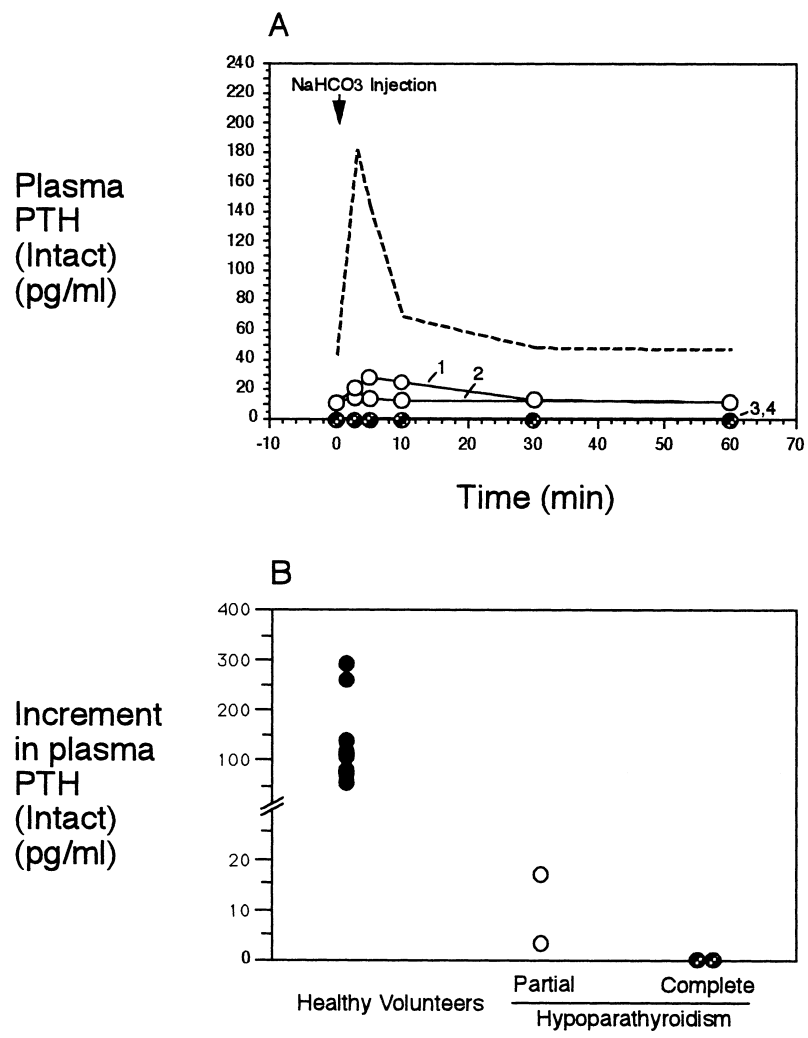

Fig. 3. Effects of sodium bicarbonate infusion on plasma PTH levels in four patients with primary hypoparathyroidism. Panel A shows the time course of the plasma intact PTH concentrations in each patient during the test. Dotted line shows the mean response in healthy volunteers. Panel B shows the absolute increment in plasma intact PTH (peak value minus value at time zero) in patients (right, middle) and in healthy volunteers (left). 
Table 2. Change in the plasma ionized calcium and blood bicarbonate ion concentrations during the sodium bicarbonate infusion in patients with parathyroid diseases

\begin{tabular}{cccccccc}
\hline \multirow{2}{*}{ Patients } & \multicolumn{2}{c}{ Plasma ionized calcium $(\mathrm{mmol} / \mathrm{L})$} & & \multicolumn{3}{c}{ Blood bicarbonate ion $(\mathrm{mmol} / \mathrm{L})$} \\
\cline { 2 - 3 } \cline { 7 - 8 } & Basal & nadir & decrement & & Basal & peak & increment \\
\hline 1 & 1.10 & 1.01 & 0.09 & & ND & ND & - \\
2 & 1.10 & 1.03 & 0.07 & & 25.9 & 30.6 & 4.5 \\
3 & 1.12 & 1.05 & 0.07 & & 26.8 & 31.2 & 4.4 \\
4 & 1.17 & 1.08 & 0.09 & & 22.1 & 28.1 & 6.0 \\
5 & 1.27 & 1.19 & 0.08 & & 22.4 & 28.2 & 5.8 \\
6 & 1.27 & 1.18 & 0.09 & & ND & ND & - \\
7 & 1.29 & 1.19 & 0.10 & & 26.5 & 31.2 & 4.7 \\
8 & 1.42 & 1.30 & 0.12 & & 23.2 & 29.8 & 6.6 \\
9 & 1.39 & 1.32 & 0.07 & & 25.9 & 29.1 & 3.2 \\
10 & ND & ND & ND & & ND & ND & - \\
\hline
\end{tabular}

a) $\mathrm{ND}$, not determined

A
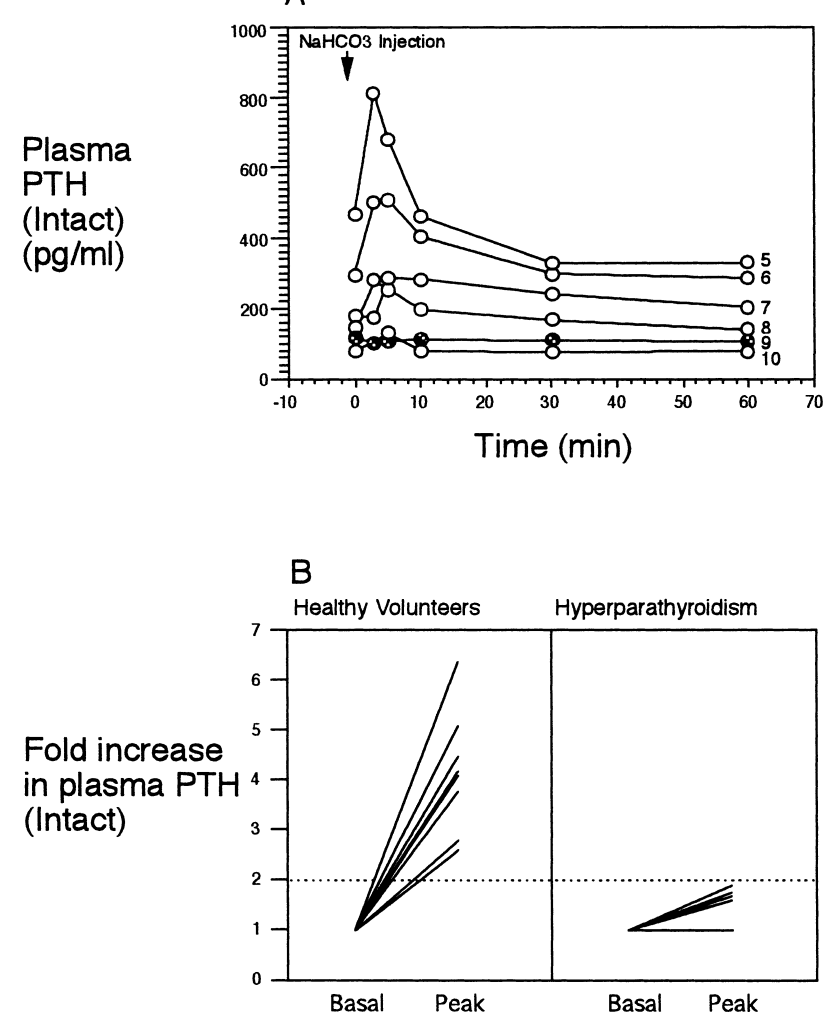

Fig. 4. Effects of sodium bicarbonate infusion on plasma PTH levels in six patients with primary hyperparathyroidism. Panel A shows the time course of the plasma intact PTH concentrations in each patient during the test. Shaded circles represent the data obtained in Patient 9, in which no PTH responses were observed. Panel B shows the fold increase of the hormone in patients (right) and in healthy volunteers (left). sponse in intact plasma PTH was observed. Similar results were also obtained in midregion and carboxyterminus PTHs (data not shown). Changes in plasma ionized calcium and blood bicarbonate concentrations during the test in each patient are summarized in Table 2.

No significant side effect was observed during the test, except that transient oral paresthesia was recognized in some subjects (both in patients and in healthy volunteers).

\section{Discussion}

In this study, we developed a new provocation test, sodium bicarbonate infusion, for the evaluation of parathyroid gland function. Using this procedure, we showed that, in healthy subjects, a prompt and brisk rise in plasma PTH occurred following a minimal decrease in plasma ionized calcium and an increase in blood $\mathrm{pH}$. We also found that PTH responses were significantly altered in patients with hyper- or hypoparathyroidism. No noticeable side effects were observed during the test. Therefore, we believe that this test may be clinically useful in delineating decreased and/or disordered parathyroid gland function.

The secretion of PTH is well known to be negatively regulated by extracellular ionized calcium levels $[1,2$, 10]. The principle of our new method is to stimulate PTH secretion by temporarily decreasing ionized calcium with the injection of sodium bicarbonate. Indeed, in healthy volunteers, marked PTH responses (on aver- 
age 4.3-fold increase in plasma intact PTH) were identified immediately following the injection. Similar responses were observed in midregion and carboxyterminus PTH levels, but less markedly, probably because of the differences in the metabolic clearance rate of each fragment $[11,12]$; i.e., the slower the clearance, the higher the basal value and thus a diminished response of de novo secretion. It is interesting that the intact PTH response observed in this study was only transient despite a sustained decrease in ionized calcium during the test. These findings appear to suggest that PTH secretion is regulated not only by the absolute value but also by the rate of change of ionized calcium.

In hypoparathyroidism, decreased or no responses of intact PTH during the test was observed. Especially noteworthy was the fact that, in partial hypoparathyroidism with measurable basal intact $\mathrm{PTH}$, very little or virtually no additional PTH release was observed. We believe that these observations may be caused by the decrease in parathyroid cell mass. In these patients, the near normal 'basal' PTH level seems to represent the almost maximally stimulated value as well, because of the diminished or abolished additional responses during the test. Since it has previously been difficult to evaluate the parathyroid gland reserve, this test should be particularly useful in the clinical setting.

In primary hyperparathyroidism, the $\mathrm{PTH}$ responses were preserved but blunted (less than two-fold) in all of the cases examined. The diminished responses may apparently be explained by the shifted range in the change of ionized calcium during the test. However, the inverse sigmoidal curve for the ionized calciumPTH relationship itself is known to be deviated to the right as well in patients with parathyroid adenoma [13] and thus the decrease in ionized calcium in a higher range should also be a comparable stimulus for PTH release. The decreased response of this hormone might reflect abnormalities in the calcium responsiveness of hormone-secreting cells. For instance, the expression of calcium sensing receptors have been shown to be decreased in parathyroid adenomas [14, $15]$, and thus the variability in the diminished response might be partly explained by the degree of decrease in the calcium sensing system of adenoma tissues. Another possibility is that the function of calcium sensing receptors is defective in tumor tissues because of the inactivating mutation of the receptor gene, although Cetani and colleagues recently showed no evidence of mutations in sporadic parathyroid adenoma [16].

An EDTA infusion test has been previously used for stimulating PTH release [3, 4]. However, it is not widely used now because of adverse cardiovascular effects. Instead, sodium citrate infusion is now being applied for the full characterization of the PTHcalcium relationship (inverted sigmoidal curve) [17]. The sodium bicarbonate infusion test described in this study does not provide the relationship because of the acuteness of the stimulation, and thus for this purpose, sodium citrate infusion appears to be more adequate [17]. In addition, our test is not recommended for hypoparathyroid patients with clinically overt hypocalcemia, because further decreases in ionized plasma calcium may worsen the symptoms of hypocalcemia, and in such cases, this test might better be done after near normalization of serum ionized calcium with adequate replacement therapy, as was performed successfully in this study.

In conclusion, the sodium bicarbonate infusion test is simple, safe, and suitable for rapid evaluation of parathyroid gland function. In particular, with this procedure, partial subclinical hypoparathyroidism, which was, to date, previously difficult to recognize, will be easily detected. This test may also be applicable for the diagnosis of other parathyroid disorders or for the estimation of residual or transplanted parathyroid gland function following surgery [18]. Further accumulation of clinical data will clarify the values and limits of this test.

\section{Acknowledgements}

We wish to thank Mitsubishi Chemical Co. (Tokyo, Japan) for providing us with the intact PTH IRMA kit used in this study. 


\section{References}

1. Aurbach GD (1973) Biosynthesis, secretion and mechanism of action of parathyroid hormone. Trans Am Clin Climatol Assoc 85: 78-99.

2. Brown EM (1991) Extracellular $\mathrm{Ca}^{2+}$ sensing, regulation of parathyroid cell function, and role of $\mathrm{Ca}^{2+}$ and other ions as extracellular (first) messengers. Physiol Rev 71: 371-411.

3. Jones KH, Fourman P (1963) Edetic-acid test of parathyroid insufficiency. Lancet 2: 119-121.

4. Burckhardt P, Tscholl-Ducommun J, Ruedi B (1980) Parathyroid response to EDTA in hypoparathyroidism and in tetany. Acta Endocrinol (Copenh) 94: 346-353.

5. Fujimoto S, Watanabe T, Yukawa K, Sakamoto A (1968) Studies on the physical surface area of Japanese. Nippon Eiseigaku Zasshi 23: 437-442 (in Japanese).

6. Takami H (1997) Basic and clinical studies on intact PTH IRMA 'Mitsubishi' kit for measuring intact PTH concentration. Clin Endocrinol (Tokyo) 45: 505-508 (in Japanese).

7. Togashi K, Fujita S, Ando K, Marumo F (1988) Fundamental and clinical evaluation on PTH midregion RIA kit (PTH kit "Yamasa") for serum PTH. Rinsho Byori 36: 974-978 (in Japanese).

8. Gorog RH, Hakim MK, Thompson NW, Rigg GA, McCann DS (1982) Radioimmunoassay of serum parathyrin: comparison of five commercial kits. Clin Chem 28: 87-91.

9. Davis OK, Hawkins DS, Rubin LP, Posillico JT, Brown EM, Schiff I (1988) Serum parathyroid hormone $(\mathrm{PTH})$ in pregnant women determined by an immunoradiometric assay for intact PTH. J Clin Endocrinol Metab 67: 850-852.

10. Okazaki R, Matsumoto T, Furukawa Y, Fujimoto Y, Niimi H, Seino Y, Fujita T, Nagataki S, Ogata E (1992) Serum intact parathyroid hormone concentration measured by a two-site immunoradiometric assay in normal subjects and patients with various parathyroid dis- orders. Endocrinol Jpn 39: 115-120.

11. Nussbaum SR, Potts JT Jr (1991) Immunoassays for parathyroid hormone 1-84 in the diagnosis of hyperparathyroidism. Bone Miner Res 6 (Suppl 2): S43-50.

12. Tanaka Y, Funahashi H, Imai T, Tominaga Y, Takagi $H$ (1997) Parathyroid function and bone metabolic markers in primary and secondary hyperparathyroidism. Semin Surg Oncol 13: 125-133.

13. Mizunashi K, Furukawa Y, Goto MM (1998) Ratio of baseline level/maximum level of serum PTH in pseudohypoparathyroidism and primary hyperparathyroidism. Calcif Tissue Int 62: 99-103.

14. Kifor O, Moore FD Jr, Wang P, Goldstein M, Vassilev P, Kifor I, Hebert SC, Brown EM (1996) Reduced immunostaining for the extracellular $\mathrm{Ca}^{2+}$-sensing receptor in primary and uremic secondary hyperparathyroidism. J Clin Endocrinol Metab 81: 1598-1606.

15. Gogusev J, Duchambon P, Hory B, Giovannini M, Goureau Y, Sarfati E, Drueke TB (1997) Depressed expression of calcium receptor in parathyroid gland tissue of patients with hyperparathyroidism. Kidney Int 51: 328-336.

16. Cetani F, Pinchera A, Pardi E, Cianferotti L, Vignali E, Picone A, Miccoli P, Viacava P, Marcocci C (1999) No evidence for mutation in the calcium-sensing receptor gene in sporadic parathyroid adenomas. $J$ Bone Miner Res 14: 878-882.

17. Grant FD, Conlin PR, Brown EM (1990) Rate and concentration dependence of parathyroid hormone dynamics during stepwise changes in serum ionized calcium in normal humans. J Clin Endocrinol Metab 71: 370-378.

18. Feldman AL, Sharaf RN, Skarulis MC, Bartlett DL, Libutti SK, Weinstein LS, Marx SJ, Norton JA, Fraker DL, Alexander HR (1999) Results of heterotopic parathyroid autotransplantation: a 13-year experience. Surgery 126: 1042-1048. 